\title{
Association between alcohol use and HIV status: findings from Zambia and Zimbabwe
}

\author{
Godfrey Musuka ${ }^{1 *}$, Farirai Mutenherwa², Zindoga Mukandavire ${ }^{3}$, Innocent Chingombe \\ and Munyaradzi Mapingure ${ }^{1}$
}

\begin{abstract}
Objective: To conduct statistical analysis to assess the association between alcohol use and HIV status using Demographic Health Survey data from Zambia (2013-2014) and Zimbabwe (2015-2016).

Results: The study showed an association between alcohol use and HIV status using nationally representative population-based surveys. The surveys were conducted among men (15-54 years) and women (15-49 years) in 2013-2014 and 2015-2016 in Zambia and Zimbabwe respectively. HIV prevalence in the two countries was higher among males and females who drank alcohol compared to those who did not. This study reinforces the existing knowledge base on the association between alcohol use and HIV sero-status and calls for further research to explore the causal pathways between alcohol consumption and HIV status.
\end{abstract}

Keywords: Alcohol use, HIV risk factors, Zimbabwe, Zambia, Demographic and Health Surveys

\section{Introduction}

The harmful use of alcohol is one of the major public health and social problems facing the world today. Its health consequences are devastating and evident in the morbidity and mortality rates associated with alcohol consumption. It has been argued that a causal relationship exists between harmful use of alcohol and infectious diseases such as tuberculosis and HIV/AIDS $[1,2]$ and the causal pathways are well documented as summarized below.

Consumption of alcohol before sex or being intoxicated during sex is linked to risky sexual behaviors and acquisition of sexually transmitted diseases, HIV included [3]. Alcohol also decreases the cognitive capacity of an individual to correctly assess risk and increases attention to sexual stimulation [4]. There is also a gender dimension to the causal pathways. For instance, women whose partners become drunk are more likely to report physical, emotional and sexual spousal violence $[5,6]$ compared to those with partners who do not get drunk.

*Correspondence: gm2660@columbia.edu

${ }^{1}$ ICAP at Columbia University, Harare, Zimbabwe

Full list of author information is available at the end of the article
Despite the increasing evidence, the role of alcohol as a risk factor for HIV is still overlooked hence important opportunities for interventions may be missed [7, 8]. Comprehensive statistical data and empirical studies on harmful use of alcohol using population-based samples are also scanty.

This study sought to highlight the association between alcohol consumption and HIV status using data from two national demographic and health surveys from Zambia and Zimbabwe where data on alcohol consumption were collected during the last surveys [5,9]. The two countries are reported in this letter as case studies. We discuss some key policy recommendation based on the results.

\section{Main text \\ Methods \\ Study area and data sources}

The study area was Zambia and Zimbabwe, two countries in southern Africa. These countries are severely affected by the HIV pandemic [10]. This study uses data from the most recent demographic and health surveys conducted in 2013-2014 for Zambia and 2015-2016 for Zimbabwe. Study participants were enrolled in both surveys using a two-stage sampling procedure to identify eligible households and participants. This study uses data from 
1122 Enumeration Areas (EAs) selected from Zambia (722) and Zimbabwe (400). Study participants were adult individuals aged 15-54 years. Data was collected from 26,366 women and 23,069 men from the two countries. For this study anonymous HIV testing was implemented with informed consent obtained for every sampled individual. For Zimbabwe, HIV serostatus was determined by testing with the enzyme-linked immunosorbent assay (ELISA) Vironostika Uniform $2 \mathrm{Ag} / \mathrm{AB}$. Additionally, all samples testing positive and a randomly selected sample of $10 \%$ of samples testing negative were retested with a follow up ELISA, the Enzygnost ${ }^{\circledR}$ HIV Integral II assay (Siemens). Those samples testing positive to the two tests were categorized as being HIV positive. If the first and second tests were discordant, the two ELISAs were then repeated; if the results remained discordant, a confirmatory test, the HIV 2.2 western blot (DiaSorin), was then used as a tie breaker. In the case of Zambia, a fourthgeneration ELISA HIV test was used as a screening and confirmatory test. A negative result on the first test was considered negative and no additional testing was conducted unless if it was selected for internal quality control purposes. All positive results on the initial test were subjected to an additional confirmatory testing ELISA, Enzygnost ${ }^{\circledR}$ HIV Integral II Assay (Dade Behring). Samples testing positive to the second test were considered positive $[5,6]$.

\section{Statistical analysis}

We used STATA Version 15.1, Texas USA to conduct our statistical analysis. We conducted Chi square test to determine the association between alcohol consumption and HIV positivity.

\section{Results}

Table 1 shows that HIV prevalence in Zambia during the 2013-2014 DHS was higher among males and females who drank alcohol compared to those who did not. Similarly, in Zimbabwe the 2015-2016 DHS show that HIV prevalence was higher among males who ever drank alcohol (15.1\%) compared to those who never drank (7.4\%), $\mathrm{p}<0.001$. The same is observed for females with $22.3 \%$ positivity among those who ever drank alcohol and $15.9 \%$ among those who never drank, $\mathrm{p}<0.001$.

\section{Discussion}

The results from the two surveys suggest that that there is a strong association between alcohol consumption and HIV positivity $(\mathrm{p}<0.001)$. This attests to earlier observations $[4,8,11]$ that alcohol consumption may increase risk-taking behaviors among individuals who may not have taken the same risk when they are sober, which potentially exposes them to HIV infection. For example, sex under the influence of alcohol was associated with a greater likelihood for paying for sex, use of physical force to have sex [12] and unprotected sex [11]. Alcohol consumption has also been suggested to increase the risk of becoming infected with HIV through its suppressive effects on the immune system [3].

Our findings reinforces results from previous studies $[1,3,6,8,12]$ that alcohol is a potential risk factor for HIV and will stimulate scholarly debate and support the need for further research to establish whether a causal relationship exists between alcohol consumption and HIV status. Such empirical studies will contribute towards understand of structural drivers of HIV and the development of comprehensive evidence-based policies and population-specific HIV prevention interventions.

\section{Limitations}

DHS are cross-sectional studies, which do not provide the causal relationships. For example, it is not possible to establish whether people acquire HIV because they drink alcohol or they drink alcohol because they are already

\begin{tabular}{|c|c|c|c|c|c|c|}
\hline \multirow[t]{2}{*}{ Variable } & \multicolumn{3}{|l|}{ Males n (\%) } & \multicolumn{3}{|c|}{ Females n (\%) } \\
\hline & HIV positive & HIV negative & p value & HIV positive & HIV negative & $p$ value \\
\hline \multicolumn{7}{|c|}{ Zambia DHS 2013-2014 } \\
\hline \multicolumn{7}{|c|}{ Drink alcohol } \\
\hline No & $841(9.7)$ & $7814(90.3)$ & $<0.001$ & 1966 (13.6) & $12,000(86.4)$ & $<0.001$ \\
\hline Yes & $731(15.1)$ & $4187(84.9)$ & & $362(26.7)$ & $1057(73.3)$ & \\
\hline \multicolumn{7}{|c|}{ Zimbabwe DHS 2015-2016 } \\
\hline \multicolumn{7}{|c|}{ Ever drank alcohol } \\
\hline No & $268(7.4)$ & $3293(92.6)$ & $<0.001$ & $1321(15.9)$ & $6573(84.1)$ & $<0.001$ \\
\hline Yes & $621(15.1)$ & $3236(84.9)$ & & $262(22.3)$ & $897(77.7)$ & \\
\hline
\end{tabular}


infected. Additionally, by design, the surveys only interview women age 15-49 years and men age 15-54 years hence the practices of adolescents, most of whom are risk-takers, are missed in such surveys.

\section{Abbreviations}

EA: Enumeration Areas; ELISA: enzyme-linked immunosorbent assay; HIV: human immunosuppression virus; DHS: Demographic Health Survey.

\section{Authors' contributions}

All authors (GM, FM, MM, IC and ZM) conceived the study. GM and MM carried out the statistical analysis. All authors (GM, FM, MM, IC and ZM) participated in the drafting of the manuscript. GM and FM wrote the first draft of the paper. All authors read and approved the final manuscript

\section{Author details}

${ }^{1}$ ICAP at Columbia University, Harare, Zimbabwe. ${ }^{2}$ Biomedical Research \& Training Institute, Harare, Zimbabwe. ${ }^{3}$ Department of Global Health and Development, London School of Hygiene \& Tropical Medicine, London, UK.

\section{Acknowledgements}

Not applicable.

\section{Competing interests}

The authors declare that they have no competing interests.

\section{Availability of data and materials}

Data will be available upon request from the corresponding author. The full datasets are available from: https://dhsprogram.com/data/available-datasets. $\mathrm{cfm}$.

\section{Consent for publication}

Not applicable.

\section{Ethics approval and consent to participate}

Procedures and questionnaires for both the Zambia and the Zimbabwe Demographic Health Surveys were reviewed and approved by the Tropical Disease Research Centre (Zambia) and the Medical Research Council of (Zimbabwe) Ethical Review Committees, respectively. Additionally, consent was obtained for all participants and include whether consent was obtained from a parent or guardian on behalf of any participants under the age of 16 .

\section{Funding}

Not applicable.

\section{Publisher's Note}

Springer Nature remains neutral with regard to jurisdictional claims in published maps and institutional affiliations.
Received: 14 June 2018 Accepted: 24 July 2018

Published online: 27 July 2018

\section{References}

1. Parry CDH, Tomlinson M, Bryant K, Rotherham-Borus MJ. Fresh perspectives on the alcohol and HIV Nexus: a call for action in an era of increased opportunities and challenges. AIDS Behav. 2017;21(Suppl 2):121-5.

2. Rehm J, Gmel GE Sr, Gmel G, Hasan OSM, Imtiaz S, Popova S, Probst C, Roerecke M, Room R, Samokhvalov AV, et al. The relationship between different dimensions of alcohol use and the burden of disease - an update. Addiction (Abingdon, England). 2017;112(6):968-1001.

3. Fritz KEWG, Bassett MT, McFarland WC, Routh JA. The association between alcohol use, sexual risk behavior, and HIV infection among men attending beerhalls in Harare, Zimbabwe. AIDS Behav. 2002;6:221-8.

4. Davis KC, Hendershot SC, George WH, Norris J, Heiman JR. Alcohol's effects on sexual decision making: an integration of alcohol myopia and individual differences. J Stud Alcohol Drugs. 2007;68:843-51.

5. Zimbabwe National Statistics Agency and ICF International. Zimbabwe Demographic and Health Survey 2015: final report. Rockville: Zimbabwe National Statistics Agency and ICF International; 2016.

6. Mthembu JC, Khan G, Mabaso ML, Simbayi LC. Intimate partner violence as a factor associated with risky sexual behaviours and alcohol misuse amongst men in South Africa. AIDS Care. 2016;28(9):1132-7.

7. Ferreira-Borges C, Rehm J, Dias S, Babor T, Parry CD. The impact of alcohol consumption on African people in 2012: an analysis of burden of disease. Trop Med Int Health. 2016;21(1):52-60.

8. Shuper PA, Neuman M, Kanteres F, Baliunas D, Joharchi N, Rehm J. Causal considerations on alcohol and HIV/AIDS-a systematic review. Alcohol Alcohol (Oxford, Oxfordshire). 2010;45(2):159-66.

9. Central Statistical Office (CSO) [Zambia], Ministry of Health (MOH) [Zambia], International. I. Zambia Demographic and Health Survey 2013-14. Rockville: Central Statistical Office/Zambia, Ministry of Health/Zambia; 2014.

10. January J, Madhombiro M, Chipamaunga S, Ray S, Chingono A, Abas M. Prevalence of depression and anxiety among undergraduate university students in low- and middle-income countries: a systematic review protocol. Syst Rev. 2018;7(1):57.

11. Kiene SM, Barta WD, Tennen H, Armeli S. Alcohol, helping young adults to have unprotected sex with casual partners: findings from a daily diary study of alcohol use and sexual behavior. J Adolesc Health. 2009:44(1):73-80.

12. Bello B, Moultrie H, Somji A, Chersich MF, Watts C, Delany-Moretlwe S. Alcohol use and sexual risk behaviour among men and women in innercity Johannesburg, South Africa. BMC Public Health. 2017;17(Suppl 3):548

\footnotetext{
Ready to submit your research? Choose BMC and benefit from:

- fast, convenient online submission

- thorough peer review by experienced researchers in your field

- rapid publication on acceptance

- support for research data, including large and complex data types

- gold Open Access which fosters wider collaboration and increased citations

- maximum visibility for your research: over 100M website views per year
}

At $\mathrm{BMC}$, research is always in progress.

Learn more biomedcentral.com/submissions 